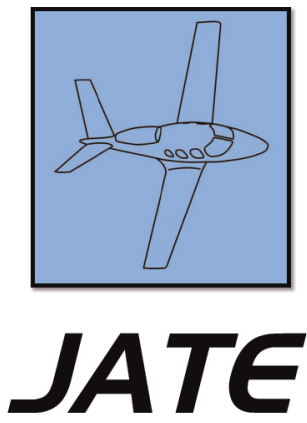

Journal of Aviation Technology and Engineering 3:2 (2014) 44-56

\title{
Safety Culture Perceptions in a Collegiate Aviation Program: A Systematic Assessment
}

\author{
Daniel Kwasi Adjekum
}

University of North Dakota

\begin{abstract}
An assessment of the perceptions of respondents on the safety culture at an accredited Part 141 four year collegiate aviation program was conducted as part of the implementation of a safety management system (SMS). The Collegiate Aviation Program Safety Culture Assessment Survey (CAPSCAS), which was modified and revalidated from the existing Commercial Aviation Safety Survey (CASS), was used. Participants were drawn from flight students and certified flight instructors in the program. The survey captured the perceptions of participants on the status of the safety culture in the program. There were significant variances in the perception of respondents on the safety culture by year groups, and it was observed that respondents who had spent more years in the program had a better perception on the prevailing safety culture than those who had just entered the program. There were also significant differences in the perceptions of U.S. resident students and international contract students on the program's safety culture. The international students had a less favorable perception of the safety culture in the program. The results show that differences in national culture can have a significant effect on perceptions of the safety culture in a collegiate aviation program.
\end{abstract}

Keywords: safety culture, collegiate aviation, Safety Management Systems, perceptions, assessment

\footnotetext{
About the Author

Daniel Kwasi Adjekum is a former aircraft commander, squadron commander in the Ghana Air Force, and airline pilot. He has over 16 years of experience as an aviation safety manager, accident investigator, and Safety Management Systems (SMS) consultant for airlines and collegiate aviation organizations. He holds a Bachelor of Science degree in Physics from the Kwame Nkrumah University of Science and Technology, Kumasi, Ghana, and a Master of Science degree in Aviation from the J. D. Odegard School of Aerospace, University of North Dakota. He has an Airline Transport Pilot (ATP) license issued by the Federal Aviation Administration (FAA), Nigerian Civil Aviation Authority, and Ghana Civil Aviation Authority. He is type-rated on the Boeing 737 300-800 turbojets, Fokker F27, BN-2T transport aircraft. He also flew L-29 Dolphin and L-39 Albatross jets for the Ghana Air Force. Presently he is the principal consultant for HomeBase International, an aviation safety management consultancy in Grand Forks, North Dakota. His present projects include SMS implementation with the UND Aerospace, and his research interest is in the area of SMS implementation and control in collegiate aviation.

The author would like to acknowledge Dr. Terry von Thaden for permission to use the CASS for his research and Gary Ullrich, Bill Watson, Dr. Warren Jensen, and all of UND for their invaluable assistance. Correspondence concerning this article should be sent to kadjekum@yahoo.com.
} 


\section{Introduction}

Modern aviation operations are growing ever more complex in times of increased demand for services with decreased resources (Wensveen, 2010). Organizational factors like safety culture and regulatory oversight play significant roles in the foundation of safety in high-risk systems (von Thaden, 2008). Several high profile accidents in the late twentieth century brought considerable attention to the role of organizational safety culture and regulatory oversight in accident causation (von Thaden, 2006; Wiegmann, Zhang, von Thaden, Sharma, \& Gibbons, 2004). Accordingly, the Federal Aviation Administration has established a comprehensive and integrated procedure to encompass a national standard of system safety with the introduction of Safety Management Systems in aviation operations (Federal Aviation Administration, 2008).

Safety Management Systems provide a top-down, businesslike approach to safety and emphasize proactive and data-driven management of safety, distinct from the traditional reactionary approach (Federal Aviation Administration, 2008). The Federal Aviation Administration issued AC 120-92A to introduce the concept of Safety Management Systems to aviation service providers like collegiate aviation organizations (Part 141) under FAA SMS Guidance, Order 8000.369 and Aviation Safety (AVS) Requirements Document, Order VS 8000.367. The Airline Safety and Federal Aviation Extension Act of 2010 (Public Law 111-216) directed the FAA to issue a final rule on SMS by July 30, 2012. The FAA is systematically working on establishing requirements for U.S. aviation certificate holders to implement SMS.

The implementation of SMS and the sustenance of a positive safety culture in a collegiate aviation program can generate both economic and operational benefits. Moncton Flight College (MFC) in New Brunswick implemented SMS and managed to have a $\$ 25,000$ annual savings in insurance premiums along with a significant reduction in regulatory audit findings (Lercel, Steckel, Mondello, Carr, \& Patankar, 2011).

Continued research into proactive organizational safety culture provides a better understanding of organizational performance, accountabilities, policies, and procedures surrounding safety (von Thaden \& Gibbons, 2008). The aim of this new oversight relationship between aviation organizations and regulatory authorities is to shift away from a prescriptive era to one of proactive and systematic business-oriented safety management (Stolzer, Haldford, \& Goglia, 2011).

\section{Purpose of the Study}

The successful implementation of an SMS initiative in a collegiate aviation program is strongly influenced by the safety culture status of front-line personnel like certified flight instructors (CFIs) and flight students. The norms, perceptions, values, and attitudes toward safety of these groups of people will have an impact on the safety culture of the aviation organization (Cooper, 2000). An important component for the successful implementation of an SMS program in any aviation organization is the level of the positive status of the organizational safety culture (International Civil Aviation Organization, 2009).

The purpose of this study was to assess the perceptions of flight students and flight instructors on the status of the prevailing safety culture after the implementation of a phased process of Safety Management Systems in a collegiate flight program.

\section{Research Questions}

1. What are the differences in perception among respondents (commercial flight students and certified flight instructors) on the status of the safety culture at an accredited four year collegiate aviation program?

2. What are the differences between the perception of international contract students and indigenous U.S. students on the status of the safety culture at an accredited four year collegiate aviation program?

\section{Literature Review}

Positive organizational safety culture creates empowerment which gives responsibility and authority to all and provides a horizontal safety hierarchy so as to treat every input equal to others (Bos \& Lu, 2007). Wood (2003) commented that the feeling of involvement would motivate users of the SMS to contribute insights to safety performance. Effective safety management in the twenty-first century involves paying attention to human factors (Perezgonzalez, 2009). System components have as much potential to cause, or save, dangerous system states as technical components (Yule, 2003).

Lu, Przetak, \& Wetmore (2005) state that by paying attention to human factors, aviation organizations can identify and capture potential hazards before they manifest as accidents. One method of achieving this is by measuring the state of safety through so-called "leading" indicators such as safety culture or safety climate (Yule, 2003). These are seen as distinct from "lagging" indicators of safety, such as accidents, as they offer insight into the state of safety without the need for retrospective analyses of negative safety outcomes (von Thaden et al., 2006).

\section{Defining and Building Up a Safety Culture}

For the purposes of this study, safety culture was defined as "the set of enduring values and attitudes regarding safety issues, shared by every member of every level of an 
organization" (Piers, Montijn, \& Balk, 2009, p. 5). Safety culture also "refers to the personal dedication and accountability of individuals engaged in any activity that has a bearing on the safe provision of aviation service" (Federal Aviation Administration, 2007, appendix A-3). Without a doubt, the core accomplishment of SMS is to create a positive safety culture to maintain and further improve the entire system's safety (IATA, 2011).

\section{Summary of Safety Culture Studies in Commercial Aviation Operations}

Wiegmann et al. (2004, p. 129) reported that "few formally documented efforts have been made to assess safety culture within the aviation industry, with the notable exception of military aviation." Three studies reported a safety assessment using commercial aviation pilots. The Australian Transportation Safety Bureau (2004) and Evans, Glendon, \& Creed (2007) reported on the development of a safety culture questionnaire designed to gain insight into pilots' perceptions of workplace safety $(n=1,308)$. The questionnaire consisted of six safety factors, each with five items. These factors were based upon previous safety culture research and input from aviation safety experts. Data from half of the sample were used in an exploratory factor analysis (EFA) that resulted in a three factor model of management commitment and communication, safety training and equipment, and maintenance. A confirmatory factor analysis (CFA) on the remaining half of the sample showed the three factor model to be an adequate fit to the data.

Finally, the responses from different types of pilots (regular public transport, charter, or aerial work such as emergency medical services or agriculture) were compared on each of the four identified safety culture factors. No significant differences between the groups were found. The Australian Transportation Safety Bureau (2004) concluded that this was due to a single professional safety climate for pilots as a group, regardless of the organization for whom they worked.

Gibbons, von Thaden, \& Wiegmann (2006) developed a questionnaire designed to assess safety culture within the context of airline flight operations. Gibbons et al.'s survey consisted of 84 items, grouped into five themes. The survey was designed by examining the content of safety culture questionnaires that have been used in other High Risk Organizations (HRO). A total of 503 responses were received from a single company. After discarding 29 items and using CFA, the analysis eventually resulted in a structure of four broad factors (organizational commitment, operations personnel, informal safety system, and formal safety system), with three subfactors in each.

Block, Sabin, \& Patankar (2007) reanalyzed the responses obtained from the 281 pilots from the previous study by Patankar (2003). The purpose was to examine whether the data supported what Block described as the purpose-alignment-control (PAC) model. A pair of experts recoded the Patankar (2003) survey items in accordance with the PAC model. The proposed factors were tested using a structural equation modeling methodology. The main drivers of safety outcomes were organizational affiliation (similar to "pride in company" [Patankar, 2003]) and proactive management (partially derived from the "safety opinion" factor [Patankar, 2003]). Organizational affiliation was directly influenced by communication, and proactive management was influenced by training effectiveness and relational supervision.

Substantial research and studies in safety culture assessments have been done in the airline and maintenance organizations (Patankar, 2003; von Thaden, Kessel \& Ruengvisesh, 2008) environment as well as in the air traffic control organization (Gordon \& Kirwan, 2004), but not much has been done in assessing the safety culture in flight training organizations, especially among flight students and flight instructors. This study intends to build up the strong foundations built by parallel studies in other aviation organizations to assess the safety culture among this particular subset of aviation operations.

\section{SMS and Safety Culture in Collegiate Aviation in the United States}

Even though, presently, SMS and safety culture assessment are not regulatory requirements in the United States for aviation training organizations like collegiate and university aviation programs (FAA, 2010c), a number of SMS pilot programs are being run by some proactive university aviation departments due to the immense positive benefits that they stand to derive (Ullrich, 2012). SMS and a positive safety culture would be substantially advantageous to collegiate aviation because they perform standardized activities towards established goals (FAA, 2013).

Collegiate aviation has areas of particular risk because students may have little or no prior flight experience and because malfunctions and unusual situations have to be simulated in order to expose these students to the variety of elements as part of their routine flying activity (FAA, 2012). In other words, in flight training, pilots may perform maneuvers that should not be accomplished as part of normal flight with the added risk that this entails. Collegiate aviation has had its fair share of tragic accidents and incidents (NTSB, 2007).

There is an imperative need for controlling risk through an assessment of the prevalent safety culture inherent in the program (Patankar, 2003). There is no type-specific framework for the assessment of safety culture in collegiate aviation, and some of the few studies done have used modified survey tools more suited for airlines and airports (University of North Dakota Safety Council, 2011). The 
safety culture assessment will provide the needed data and feedback to make changes that will continuously improve safety and ensure an integrated system-wide safety net for training organizations (McCune, 2012).

\section{Components of a Positive Safety Culture}

A positive safety culture is the engine that drives the organization towards the goal of maximum attainable operational safety regardless of any formats of resistance, obstacles, and pressures (International Civil Aviation Organization, 2009). A positive safety culture promotes mutual respect among the employees and managers of the organization (Simon \& Cistaro, 2009). A positive safety culture ensures that operational hazards and errors are anticipated (Stolzer et al., 2011). There are five components of a positive safety culture, namely: informed, reporting, just, learning, and flexible cultures, as outlined in Figure 1.

\section{Methodology}

The study used the Collegiate Aviation Program Safety Culture Assessment Survey (CAPSCAS), which is a modified form of the Commercial Aviation Safety Survey (CASS), which is a validated tool developed by von Thaden and Gibbons (2008). The CASS identifies the respondents' perception of the current state as well as the strengths and weaknesses of the safety culture in an organization. The CASS was specifically modified and revalidated for collegiate aviation programs (Creswell, 2009). The adaptation and modification were done with permission from Dr. Terry von Thaden, copyright owner for CASS.

CAPSCAS was then used to assess the safety culture perception of commercial flight students and certified flight instructors. The CAPSCAS provided a baseline measure of the collegiate program's safety culture, thus obtaining a benchmark to judge critical movement and change in the aviation program's safety culture.

\section{Population}

The population ( $n=1,500$ ) for the study consisted of aviation students and certified flight instructors at the aviation department of an accredited CFR Part 141 flight training and four-year degree-awarding university in the Northwestern region of the United States. The sample $(n=$ 945) was drawn from undergraduate commercial flight students, international contract flight students, and certified flight instructors at the university. Air Traffic Control (ATC), Unmanned Aerial System (UAS), Flight Technology (FT), and graduate students (GS) were not included in this study.

\section{Survey Administration}

Participants responded to items in the survey instrument using a 5-point Likert scale (strongly disagree to strongly agree) and a nonapplicable option (Creswell, 2009). The survey was administered through an online survey tool called Qualtrics ${ }^{\circledR}$ online in the English language to allow for simplicity of delivery and anonymity of participants. Participants were assured of the confidentiality of their responses.

The survey allowed participants to have plenty of opportunities to provide more information if they wished to do so, and some open-ended questions were asked to specifically explore the nature of these activities. There were 61 items in the survey broken into the following sections: formal safety, informal safety, operational interactions, organizational commitment, safety behavior, and demographics.

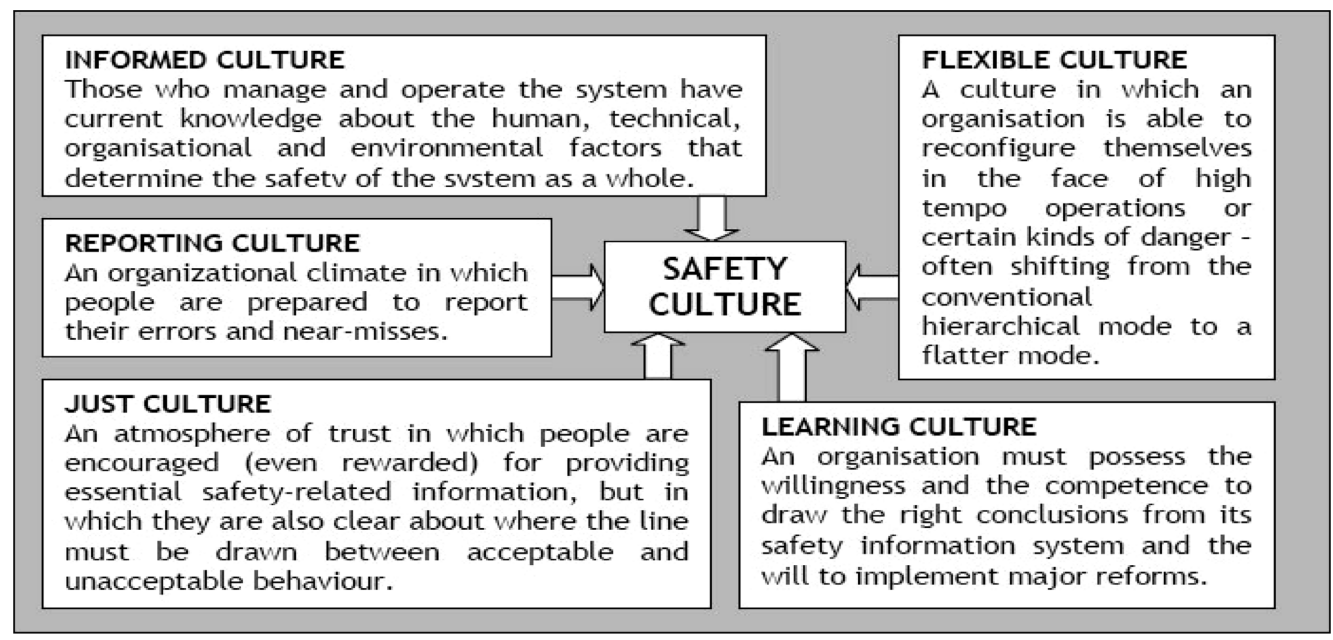

Figure 1. The components of safety culture: Definitions of informed, flexible, reporting, just and learning cultures. (Used with permission from Global Aviation Information Network, 2004.) 
Table 1

Scales inventory for the CAPSCAS

\begin{tabular}{|c|c|}
\hline CAPSCAS Major Factor Scale & Sub-factor Scales \\
\hline Formal Safety Program & $\begin{array}{l}\text { Reporting System } \\
\text { Response and feedback } \\
\text { Safety Personnel }\end{array}$ \\
\hline Informal Safety Program & $\begin{array}{l}\text { Accountability } \\
\text { Pilot Authority } \\
\text { Professionalism }\end{array}$ \\
\hline Operations Interaction & $\begin{array}{l}\text { Supervisors of Flight (SoF)/Lead Flight/ } \\
\text { Chief Flight Instructor } \\
\text { Dispatch/Ground and Ramp Personnel }\end{array}$ \\
\hline Organizational Commitment & $\begin{array}{l}\text { Safety Values } \\
\text { Safety Fundamentals } \\
\text { Going Beyond } \\
\text { Compliance }\end{array}$ \\
\hline
\end{tabular}

\section{Results and Data Analysis}

Quantitative data was imported into the SPSS ${ }^{\circledR}$ software and analyzed. All additional comments and responses were coded manually by the researcher for themes and analyzed using SPSS ${ }^{\circledR}$. Significant values were set at the 0.05 alpha levels (two-tailed). The survey was tested for content validity and reliability of scale.

\section{Content Validity}

A Principal Component Analysis (PCA) was conducted on the 61 items with orthogonal rotation (varimax). The Kaiser-Meyer-Olkin (KMO) measure verified the sampling adequacy for the analysis $(\mathrm{KMO}=0.84$ and all $\mathrm{KMO}$ values for individual items $>0.85$ ) which is well above the acceptable limit of 0.5 (Field, 2009). A Bartlett's test of sphericity $\chi^{2}(1891)=6304, \mathrm{p}<0.001$, was conducted and indicated that the correlation between items were sufficiently large for PCA. Thirteen components were extracted and had Eigen values greater than Kaiser's criterion of 1 and, in combination, explained $73.90 \%$ of the variance.

\section{Reliability}

All four major scales of the CAPSCAS (Formal Safety, Informal Safety, Operations Interaction, and Organizational Commitment) showed high reliabilities. Test reliability refers to the consistency or reliability of questionnaire items (Stevens, 2002). A reliable scale is one that will yield the same score for two different individuals with the same true level of the trait or attitude being measured, or for one individual tested twice, assuming that no changes have occurred between tests (Cronbach,1951; Cortina, 1993). Within a scale, items that assess the same underlying dimension are related or correlated with one another (Field, 2009; Creswell, 2009). The values for reliability are outlined in Table 2 and show the Cronbach's alpha values for all major scales.
Table 2

Cronbach's alpha for CAPSCAS.

\begin{tabular}{lcc}
\hline Major Scale & $\begin{array}{c}\text { Number of Items in } \\
\text { Scale }(n)\end{array}$ & Cronbach's $\alpha$ \\
\hline Formal Safety Program & 15 & 0.90 \\
Informal Safety Program & 14 & 0.85 \\
Operations Interaction & 19 & 0.87 \\
Organizational Commitment & 14 & 0.86 \\
\hline Total for CAPSCAS & $\mathbf{6 2}$ & $\mathbf{0 . 9 6}$ \\
\hline
\end{tabular}

\section{Demographic Information}

At the end of the response period, $(n=234)$ responses were obtained from the survey and comprised of fully $(n=$ 142) completed and useable responses representing a $61 \%$ return rate. About $51.7 \%$ of the respondents provided comments in the text boxes provided for extra comments. Of the total respondents, 34\% identified themselves as freshmen, $5 \%$ were sophomores, $17 \%$ were juniors, $22 \%$ were seniors, and $\mathrm{CFI} /$ others accounted for the remaining $21 \%$. This number represents respondents who answered the demographic question about their status in terms of years spent in the flight program as students and CFI at the university. Table 3 outlines the categories.

The respondents were asked about their status as either resident U.S. students or international contract students in the university's flight program. This was done to determine how many international contract students responded to the survey. The flight program at the university has a number of international contract students from predominantly Asia and the Middle East and whose national culture and perception about the safety culture of the flight program of the university may not be the same as resident U.S. students. One of the aims of the study was to find out if there was any difference in the perception on the status of the safety culture of the flight program by the two groups. Table 5 illustrates this category.

\section{Analysis of Research Questions}

An analysis of variance (ANOVA) was used to find if there were any significant differences in the mean responses of the participants on the safety culture of the flight program. A one-way independent ANOVA and post hoc (Games-Howell) analysis was used to find out which

Table 3

Category of respondents.

\begin{tabular}{lcc}
\hline Category & Number $(n)$ & Percentage $(\%)$ \\
\hline Freshmen & 46 & 34 \\
Sophomore & 7 & 5 \\
Junior & 23 & 17 \\
Senior & 30 & 22 \\
CFI/Others & 28 & 21 \\
\hline Total & $\mathbf{1 3 4}$ & $\mathbf{1 0 0}$ \\
\hline
\end{tabular}


Table 4

Gender distribution of respondents.

\begin{tabular}{lcc}
\hline Gender & Number $(n)$ & Percentage $(\%)$ \\
\hline Male & 125 & 93 \\
Female & 9 & 7 \\
\hline Total & $\mathbf{1 3 4}$ & $\mathbf{1 0 0}$
\end{tabular}

groups differ in their mean responses since no specific hypothesis was generated before the research (Field, 2009). There was a significant difference in the mean responses of perception on the item "I feel like I am gambling with the safety of my aircraft every time I go on a training activity." $\mathrm{F}(4,128)=2.83, \mathrm{p}<0.05$ (two-tailed) which falls under the subscale of Ramp Operations and major scale of Operations Interaction. A post hoc analysis (GamesHowell) revealed that there were significant differences between the mean responses of juniors and freshmen, $\mathrm{p}<$ 0.05 (two-tail).

The item "My university is committed to equipping aircraft with up to date technology" under the subscale of Safety Fundamentals and scale of Organizational Commitment showed significant differences in the mean responses of respondents, $\mathrm{F}(4,126)=3.02, \mathrm{p}<0.05$. A post hoc analysis revealed significant differences in the mean responses between the juniors and freshmen, $\mathrm{p}<$ 0.05 . The other item that showed significant differences in mean responses was "Management tries to get around safety requirements whenever they get the chance." The results were $F(4,125)=3.22, p<0.05$. Further post hoc analysis revealed that there were significant differences in the mean responses of juniors and freshmen, $p<0.05$. Figure 2 displays a simple bar graph with error bars highlighting the significant differences in mean of responses to their perception of the safety culture.

For the second research question, an independent t-test was used to determine if there existed any significant differences in the mean perception of the resident U.S. students $(n=95)$ and international flight students $(n=39)$ on the safety culture of the university's flight program The variances in the samples were assumed roughly equal, and scores were independent. The mean perception on the status of the safety reporting system of the collegiate aviation program of resident U.S. students $(\mathrm{M}=4.27, \mathrm{SE}$ $=0.23$ ) was better than the international contract students $(\mathrm{M}=3.77, \mathrm{SE}=0.23)$, when asked, "The safety reporting system is convenient and easy to use." The responses were

Table 5

International student status.

\begin{tabular}{lcc}
\hline $\begin{array}{l}\text { International Student } \\
\text { Status }\end{array}$ & Number $(n)$ & Percentage (\%) \\
\hline Yes & 39 & 29 \\
No & 95 & 71 \\
\hline Total & $\mathbf{1 3 4}$ & $\mathbf{1 0 0}$ \\
\hline
\end{tabular}

Table 6

Airman certifications and ratings.

\begin{tabular}{lcc}
\hline Airman Certificates/Ratings & Number $(n)$ & Percentage (\%) \\
\hline Student & 18 & 13 \\
Private & 52 & 39 \\
Commercial Single-Engine & 7 & 5 \\
Commercial Multiengine & 20 & 15 \\
CFI & 4 & 3 \\
CFI (Instrument) & 15 & 11 \\
Multiengine Instructor (MEI) & 8 & 6 \\
Air Transport Pilot (ATP) & 3 & 7 \\
Others/Mixed Certificate & 7 & 5 \\
\hline Total & $\mathbf{1 3 4}$ & $\mathbf{1 0 0}$ \\
\hline
\end{tabular}

all above the neutral point of 3 . The differences in the mean response were also significant, $\mathrm{t}(132)=-2.59, \mathrm{p}<0.05$.

The resident U.S. students had a mean response of $(\mathrm{M}=$ $3.40, \mathrm{SE}=0.18)$ as compared to the international students who had a mean response of $(\mathrm{M}=2.49, \mathrm{SE}=0.27)$ when asked for their perception on the statement "Pilots do not bother reporting near misses or close calls, since this event does not cause any real damage." The difference was significant, $\mathrm{t}(132)=2.68, \mathrm{p}<0.05$. This shows that the contract students in their perception agreed with the item. The responses for the item "Pilots are satisfied with the way the university deals with safety reports' showed that the contract students $(\mathrm{M}=3.92, \mathrm{SE}=0.23)$ had a more positive perception than the U.S. students $(\mathrm{M}=3.37, \mathrm{SE}=$ 0.11 ), even though all of the mean responses were above the neutral point of 3 .

The differences in their responses were significant, $\mathrm{t}(132)=2.35, \mathrm{p}<0.05$. However, when the mean responses of their perception on the item "University only keeps track of major safety problems and overlooks routine ones" were compared, the resident U.S. students ( $\mathrm{M}=$ 3.92, $\mathrm{SE}=0.16)$ disagreed with the item, whereas the international students $(\mathrm{M}=2.44, \mathrm{SE}=0.27)$ who agreed with the item. The differences in their responses was significant, $\mathrm{t}(132)=-4.78, \mathrm{p}<0.05$.

Generally, there was a good perception on the item "Personnel responsible for safety hold high status in the university." The mean responses for the U.S. students $(\mathrm{M}=4.13, \mathrm{SE}=0.07)$ was higher than the international students $(\mathrm{M}=3.72, \mathrm{SE}=0.21)$. The difference in response was significant, $\mathrm{t}(130)=-2.03, \mathrm{p}<0.05$. Both groups were in strong agreement with the item "Personnel responsible for safety have power to make changes." The mean of responses for the U.S. students $(\mathrm{M}=4.34, \mathrm{SE}=$ $0.07)$ was higher than the international students $(M=3.71$, $\mathrm{SE}=0.21)$. The difference in responses was significant, $\mathrm{t}(130)=-3.45, \mathrm{p}<0.05$.

The two groups also agreed with the item "Personnel responsible for safety have a clear understanding of the risk involved in flight." The mean responses of the U.S, students $(\mathrm{M}=4.31, \mathrm{SE}=0.09)$ was higher than the international students $(\mathrm{M}=3.87, \mathrm{SE}=0.21)$, and the 


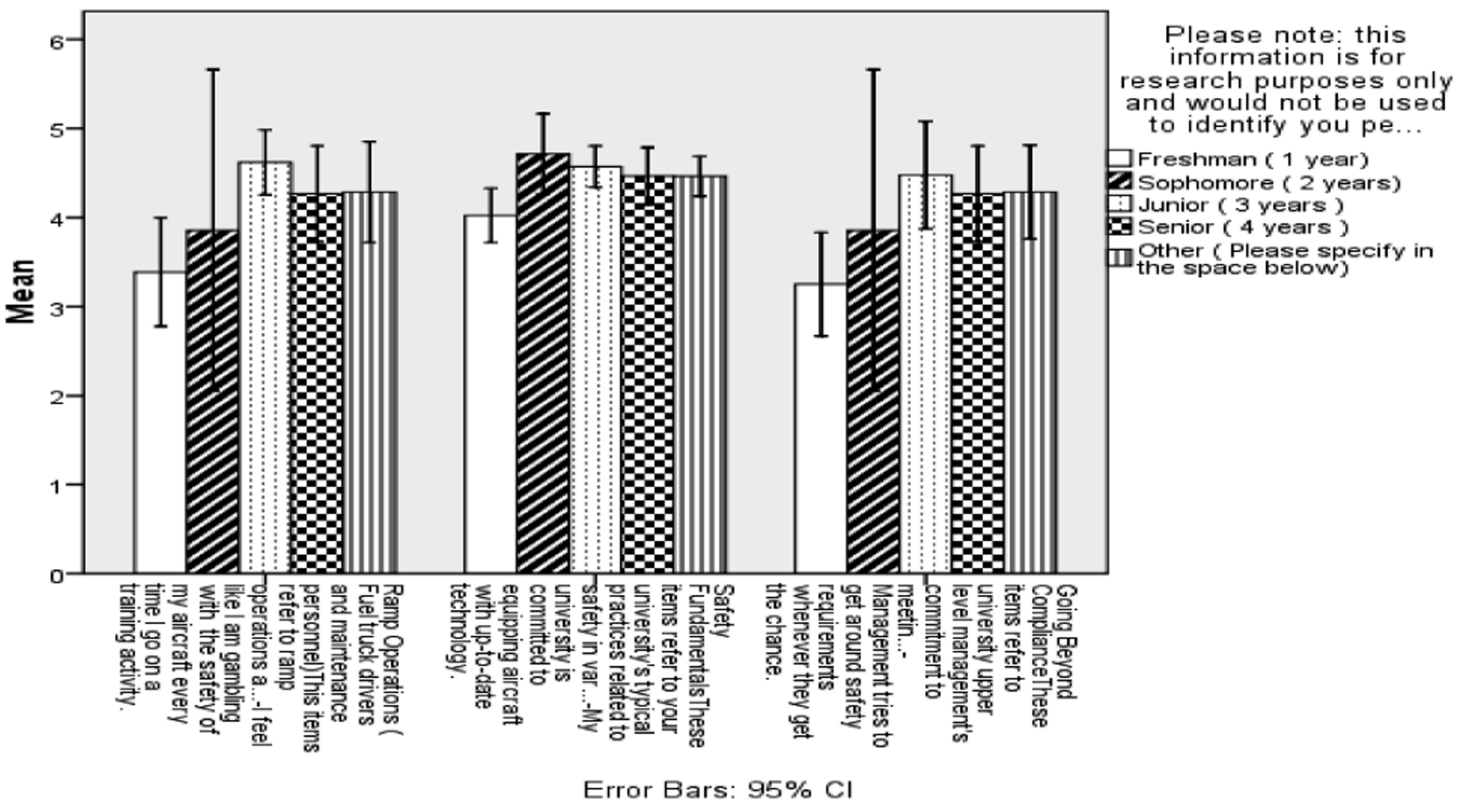

Figure 2. Simple bar graph of "mean perception of safety culture."

differences in the mean responses were significant, $t(130)$ $=-2.11, \mathrm{p}<0.05$. The item "Safety personnel have little or no authority compared to operational personnel" showed that, while the U.S. students $(\mathrm{M}=4.29, \mathrm{SE}=0.14)$ disagreed with the item, the international students $(\mathrm{M}=$ $2.03, \mathrm{SE}=0.27)$ agreed with it. There was a significant difference in the mean of their responses, $\mathrm{t}(128)=-6.63$, $\mathrm{p}<.05$.

The item "University management shows favoritism to certain pilots" showed that the perception of the U.S. students $(\mathrm{M}=3.15, \mathrm{SE}=0.18)$ were partially neutral, while the international students $(\mathrm{M}=2.03, \mathrm{SE}=0.27)$ agreed with the item. The differences in responses were significant, $\mathrm{t}(128)=-3.28, \mathrm{p}<0.05$. The international students $(\mathrm{M}=2.35, \mathrm{SE}=0.28)$ had a strong perception that "When accidents and incidents happen, management always blame the pilot" as compared to the U.S. students $(\mathrm{M}=3.39, \mathrm{SE}=0.17)$ who partially disagreed with the item. The differences in their responses were significant, $\mathrm{t}(128)=-3.12, \mathrm{p}<0.05$.

The two groups had a neutral perception that "Pilots are actively involved in identifying and resolving safety concerns." The responses of the U.S. students ( $\mathrm{M}=$ $3.23, \mathrm{SE}=0.11)$ had a lower mean as compared to the international students $(\mathrm{M}=3.82, \mathrm{SE}=0.19)$. The differences in the mean responses for both groups were significant, $\mathrm{t}(130)=2.67, \mathrm{p}<0.05$. The international students $(\mathrm{M}=2.26, \mathrm{SE}=0.28)$ had a strong perception that "Pilots who call in sick or fatigued are scrutinized by the Supervisor of Flight or other flight management personnel," while the U.S. students $(\mathrm{M}=3.69, \mathrm{SE}=$ $0.18)$ disagreed with the item. The differences in their responses were significant, $\mathrm{t}(130)=-4.25, \mathrm{p}<0.05$. The international students $(\mathrm{M}=2.53, \mathrm{SE}=0.29)$ also had a strong perception that "Pilots have little or no authority to make decisions that affect the safety of normal flight operations." The U.S. students $(\mathrm{M}=3.45$, $\mathrm{SE}=0.13)$, however, disagreed with the item. The differences in their responses were significant $\mathrm{t}(130)=-3.86, \mathrm{p}<0.05$.

The U.S. students $(\mathrm{M}=2.88, \mathrm{SE}=0.12)$ disagreed with the item "Pilots who are new and less senior are willing to speak up regarding flight safety issues," while the international students $(\mathrm{M}=3.55, \mathrm{SE}=0.21)$ agreed. There was a significant difference in their responses $\mathrm{t}(130)=$ $2.80, \mathrm{p}<0.05$. The U.S. students $(\mathrm{M}=2.47, \mathrm{SE}=0.09)$, however, disagreed that "Pilots never cut corners or compromise safety, regardless of the operational pressures to do so" while the international students $(\mathrm{M}=3.55, \mathrm{SE}=$ $0.21)$ agreed. There were significant differences in their responses, $\mathrm{t}(130)=4.79, \mathrm{p}<0.05$.

The international students $(\mathrm{M}=2.59, \mathrm{SE}=0.33)$ agreed with the item "Chief/Lead CFIs and Supervisors of Flight are unavailable when pilots need help," while the U.S. students $(\mathrm{M}=4.19, \mathrm{SE}=0.16)$ disagreed. The differences between their response were significant, $\mathrm{t}(127)=-4.19, \mathrm{p}$ $<0.05$. The international students $(\mathrm{M}=2.88, \mathrm{SE}=0.32)$ had a perception that "As long as there are no accidents or incidents, Chief/Lead CFIs and Supervisors of Flight don't care how flight operations are performed," while the U.S. students $(\mathrm{M}=4.91, \mathrm{SE}=0.16)$ disagreed. The differences in their responses were significant, $\mathrm{t}(127)=-3.92, \mathrm{p}<$ 0.05 .

The international students $(\mathrm{M}=2.79, \mathrm{SE}=0.34)$ agreed with the item "Dispatch inappropriately uses MEL, when it is better to fix equipment." The U.S. students ( $\mathrm{M}=4.48$, $\mathrm{SE}=0.12)$ strongly disagreed. The differences in responses were significant, $\mathrm{t}(126)=-5.80, \mathrm{p}<0.05$. The U.S. students $(\mathrm{M}=4.27, \mathrm{SE}=0.14)$ disagreed with 
the item "Dispatch would rather take a chance with safety than cancel a flight." The international students $(\mathrm{M}=2.06$, $\mathrm{SE}=0.29)$ strongly agreed. The differences in their responses were significant, $\mathrm{t}(127)=-7.35, \mathrm{p}<0.05$.

Both U.S, students $(\mathrm{M}=4.28, \mathrm{SE}=0.05)$ and international students $(\mathrm{M}=3.91, \mathrm{SE}=0.18)$ agreed with the item "Instructors/trainers have a clear understanding of the risk associated with operations." The differences in their responses were significant, $\mathrm{t}(126)=-2.49, \mathrm{p}<0.05$. Both U.S. students $(\mathrm{M}=4.31, \mathrm{SE}=0.13)$ and international students $(\mathrm{M}=3.91, \mathrm{SE}=0.18)$ all agreed on the item "Safety is consistently emphasized during training at my university." There was a significant difference in their responses, $\mathrm{t}(126)=-2.33, \mathrm{p}<0.05$. The international students $(\mathrm{M}=2.21, \mathrm{SE}=0.31)$ had a perception that "Instructors/trainers teach shortcuts and ways to get around safety requirements" while the U.S. students $(\mathrm{M}=4.24, \mathrm{SE}=0.13)$ disagreed. The differences in their responses were significant, $\mathrm{t}(126)=-6.89, \mathrm{p}<$ 0.05 .

U.S. students $(\mathrm{M}=4.17, \mathrm{SE}=0.07)$ and the international students $(\mathrm{M}=3.76, \mathrm{SE}=0.18)$ agreed on the item "Ramp personnel are careful about position of equipment (fuel trucks, power carts, etc.)." There was significance in the differences in their responses, $\mathrm{t}(131)=$ $-2.41, \mathrm{p}<0.05$. The international students $(\mathrm{M}=2.63, \mathrm{SE}$ $=0.31$ ) had a perception that "Ramp personnel are careless about removing debris (e.g. cups, rags, tools, clothing, etc.) near the aircraft, which may pose FOD hazards." The U.S students $(\mathrm{M}=4.28, \mathrm{SE}=0.14)$ did not agree with this item. The differences in their responses were significant, $\mathrm{t}(130)=-5.49, \mathrm{p}<0.05$. International students $(\mathrm{M}=$ 2.47, $\mathrm{SE}=0.31$ ) agreed with the item "I feel like I am gambling with the safety of my aircraft every time I go on a training activity" while the U.S. students $(\mathrm{M}=4.65, \mathrm{SE}=$ $0.10)$ disagreed. The differences in their response were significant, $\mathrm{t}(131)=-8.54, \mathrm{p}<0.05$.

U.S. students $(\mathrm{M}=3.76, \mathrm{SE}=0.16)$ disagreed with the item "Management is more concerned with making money than being safe" while the international students $(\mathrm{M}=$ $2.58, \mathrm{SE}=0.31)$ agreed. The differences in their responses was significant, $\mathrm{t}(128)=-3.57, \mathrm{p}<0.05$. International students $(\mathrm{M}=2.84, \mathrm{SE}=0.31)$ agreed with the item "Management does not show much concern for safety until there is an accident or incident," while the U.S. students (M $=4.14, \mathrm{SE}=0.15)$ disagreed. Both U.S. students $(\mathrm{M}=$ 4.34, $\mathrm{SE}=0.06)$ and international students $(\mathrm{M}=3.97, \mathrm{SE}$ $=0.18$ ) agreed with the item "My university flight manual is carefully kept up to date." The differences in their responses were significant, $\mathrm{t}(129)=-2.18, \mathrm{p}<0.05$.

U.S. students $(\mathrm{M}=4.16, \mathrm{SE}=0.08)$ and international students $(\mathrm{M}=3.79, \mathrm{SE}=0.18)$ both agreed with the item "My university is willing to invest money, resources, and effort to improve safety." The differences between the responses were significant, $\mathrm{t}(129)=-2.18, \mathrm{p}<0.05$. The international students $(\mathrm{M}=3.87, \mathrm{SE}=0.18)$ and U.S. students $(\mathrm{M}=4.55, \mathrm{SE}=0.05)$ both agreed with the item "My university is committed to equip aircraft with up-todate technology." The differences in responses were significant, $\mathrm{t}(129)=-4.62, \mathrm{p}<0.05$. The item "My university ensures that maintenance on aircraft is adequately performed and aircraft safe to operate" was agreed on by the U.S. students $(\mathrm{M}=4.58, \mathrm{SE}=0.06)$ and international students $(\mathrm{M}=3.92, \mathrm{SE}=0.19)$. The differences in their responses were significant, $\mathrm{t}(129)=$ $-4.07, \mathrm{p}<0.05$.

The U.S. students $(\mathrm{M}=4.11, \mathrm{SE}=0.09)$ and international students $(\mathrm{M}=3.55, \mathrm{SE}=0.20)$ agreed with the item "Management goes above and beyond regulatory minimums, when it comes to issues of flight safety." The differences in their mean responses were significant, $t(128)$ $=-2.79, \mathrm{p}<0.05$. The international students $(\mathrm{M}=2.21$, $\mathrm{SE}=0.28$ ) agreed that "Management schedules CFIs as much as legally possible, with little concern for their sleep schedule or fatigue." The U.S. students $(\mathrm{M}=3.67, \mathrm{SE}=$ $0.17)$, however, disagreed. The differences in the responses were significant, $\mathrm{t}(128)=-4.48, \mathrm{p}<0.05$.

The U.S. students $(\mathrm{M}=4.61, \mathrm{SE}=0.11)$ disagreed that "Management tries to get around safety requirements whenever they get the chance." The international students $(\mathrm{M}=2.32, \mathrm{SE}=0.28)$ agreed with the item and the differences in the responses of the two groups were significant, $\mathrm{t}(128)=-9.10, \mathrm{p}<0.05$. Finally, both U.S. students $(\mathrm{M}=4.09, \mathrm{SE}=0.10)$ and international students $(\mathrm{M}=3.68, \mathrm{SE}=0.20)$ agreed that "Management views violations very seriously even when they don't result in any serious damage or injury." The differences in their responses were significant, $\mathrm{t}(128)=-2.00, \mathrm{p}<0.05$.

\section{Discussion}

\section{Perception of Safety Culture Among Respondents}

The first part of the discussion sought to deal with the research question, "What are the differences in perception among respondents [commercial flight students and certified flight instructors] on the status of the safety culture at an accredited four year collegiate aviation program?" The research question was to find out the level of variability in the perception of flight students and flight instructors on the safety culture in the university's flight program.

A good measure of consistency in the safety culture of an organization is to focus on the variance in survey responses (von Thaden \& Gibbons, 2008). When a population demonstrates considerable variance, the coherent structure for an underlying culture of safety is, for all intents and purposes, nonexistent and shows that there are gaps in the purpose, alignment, and control of the safety management (Patankar, 2003). 
The results showed that respondents had a good perception and favorable outlook of the safety culture prevailing in the university's flight program. There were, however, some areas that needed improvement, and the discussion will focus more on the areas for improvement for the safety program and how the Safety Management Systems can consolidate a more proactive and positive safety culture.

There was a significant difference in the mean responses of perception on the item "I feel like I am gambling with the safety of my aircraft every time I go on a training activity," under the major scale of Operations Interaction. The significant differences were between the responses of juniors and freshmen. The results showed that, while the juniors had a more favorable perception on most items under operations interaction, the freshmen had poor perception on these items. Since the university has a standard operational procedure and curricula for all flight operations, it was expected that there would be very minimal variability of responses among the year groups. However, variability in perception can be a function of training environment, operational interaction, experience level, prior training, fleet assignment, and operational safety records (von Thaden et al., 2008).

A significant variation in responses can also be a result of the risk perception among the year groups (Block et al., 2007). A more risk-loving attitude and behavior can result in significant safety breaches in the wall of the most formidable safety management system (Reason \& Hobbs, 2003; Patankar, 2003). Concurrence is a critical feature of a healthy safety culture (von Thaden \& Gibbons, 2008; IATA, 2011), as it reflects the degree to which both juniors and freshmen share a common perception of the safety culture. It is, therefore, important for more attention to be focused on freshmen by reinforcing safety education, especially on operations interaction.

The item "My University is committed to equipping aircraft with up-to-date technology" under the subscale of Safety Fundamentals and scale of Organizational Commitment showed a significant difference in the mean responses of juniors and freshmen. There were some relevant comments from respondents:

"As per technology in the aircraft, just look at our fleet. Most of the fixed-wing are astounding. Most of the helicopters are laughable. I feel that there is not equal representation among fixed-wing and rotorcraft in terms of technology. This obviously plays a role in safety."

The quote underscores the perception that updating aircraft with new technology is skewed towards fixed-wing operation and that management should make a conscious effort to create equity in allocation of resources. It can create a perception that management is not committed to enhancing safety in some fleet of the program.
The other item that showed significant differences in mean responses was "Management tries to get around safety requirements whenever they get the chance." There were significant differences in responses between the juniors and the freshmen. From the results, the freshmen seem to have a rather poor perception about the commitment of management to safety, while the juniors had a rather good perception. The diametrical responses and measure of the perception of the commitment of management to safety potentially indicates a gap in the safety management of the flight program.

\section{Perception of International Students and U.S. Students on the Safety Culture in the Collegiate Aviation Program}

This section of the discussion focuses on the second research question: "What are the differences between the perception of international contract students and resident U.S. students on the status of the safety culture at an accredited four year collegiate aviation program?"

The perceptions of these two groups (international students and resident U.S. students) were analyzed on the basis of the impact of national culture on their perception on the safety culture (Hofstede \& Holfstede, 2004). Fanjoy \& Gao (2011), in their study on the learning style of Chinese collegiate aviation students, observes that Chinese culture is significantly different from that of the U.S. in terms of power-distance, individualism, and long-term orientation. Joy \& Kolb (2009) states that national culture has an impact on individual learning and cognitive style preferences. Hofstede \& Hofstede (2004) suggests that when students from a different cultural background are educated in a different cultural context, the impact of the cultural differences should be considered to identify any potential negative influence.

The item "Pilots do not bother reporting near misses or close calls, since this event does not cause any real damage" on the reporting system of the flight program showed that resident U.S. students disagreed with the item while the contract students, in their perception, agreed with the item. The significant differences in the responses could be a result of the level of risk perception among the two groups, as compared to a similar study on general aviation pilots by Hunter (2006). The differences in national culture and language could also affect the perception and behavior of these two groups as outlined in the research of Kanki, Helmreich \& Anca (2010) on crew management resources among multicultural crews.

When the mean responses of their perception on the item "University only keeps track of major safety problems and overlooks routine ones" were compared, the resident U.S. students disagreed with the item while the international students agreed with the item. The differences in their responses were significant. The results show similarities with the study of Dillman, Voges \& Robertson (2011), 
which showed that flight students sometimes simply do not report safety occurrences because, in their opinion, the event is not significant enough to warrant completing the paperwork, since it takes time, energy and effort. There is also the issue of effective feedback from management for the effort of reporting safety occurrences. If students do not receive tangible and timely feedback from safety management personnel on seemingly insignificant reported safety hazards and occurrences, it promotes apathy and stifles an effective safety reporting system.

The U.S. students disagreed with the item "Safety personnel have little or no authority compared to operational personnel," but the international students strongly agreed with it. There was a significant difference in the mean of their responses. This can be an indication of the perceived marginal input of safety personnel in the administration and operation of contract flight programs. The international students' perception is probably influenced by their increased interaction with the operational personnel over the safety personnel.

The item "University management shows favoritism to certain pilots" showed that the perceptions of the U.S. students were almost neutral while the international students agreed with the item. The differences in responses were significant, and this was correlated to the response to the item "When accidents and incidents happen, management always blame the pilot," where the international students strongly agreed but the U.S. students partially disagreed. This result is similar to the research findings of von Thaden et al. (2008), which suggested that a primary challenge regarding accountability concerns perceptions of favoritism. It appears that pilots are not blamed unfairly for their errors, but favored pilots may receive more beneficial outcomes than non-favored pilots (Dekker, 2007).

The international students had a strong perception that "Pilots who call in sick or fatigued are scrutinized by the Supervisors of Flight (SoF) or other flight management personnel," while the U.S. students disagreed with the item. The international students also had a strong perception that "Pilots have little or no authority to make decisions that affect the safety of normal flight operations." The U.S. students, however, disagreed. The two items, rather, send a worrying signal about the perception of the international students on their input when it comes to making decisions that can affect the safety of flight. Studies by Gordon \& Kirwan (2004) and Dillman et al. (2011) highlight the importance of personnel input in order to achieve an effective SMS.

The U.S. students disagreed with the item "Pilots who are new and less senior are willing to speak up regarding flight safety issues," while the international students agreed. This was quite unusual since Hofstede (1980), and Hofstede \& Hofstede (2004) suggest that national cultures with Low Power Distance, like those of U. S. students, have a tendency to be more assertive and bold when in a group, compared to the international students who mostly have a culture that is more of a High Power Distance which makes them less willing to challenge authority. The U.S. students, however, disagreed that, "Pilots never cut corners or compromise safety, regardless of the operational pressures to do so," while the international students agreed. National cultural values like Uncertainty Avoidance (rules and order [Hofstede, 1980; Hofstede \& Hofstede, 2005]) could largely influence this perception. Respondents provided comments to reinforce their perceptions and are quoted below:

"I think in general most pilots treat safety with respect and are professional about safety, but there are some who are much more willing to cut corners or ignore safety policies and procedures than others."

"Students are negatively impacted by not meeting flight templates which promotes them to cut corners and fly when they should not."

The international students agreed with the item "Dispatch inappropriately uses MEL when it is better to fix equipment." The U.S. students strongly disagreed. The U.S. students disagreed with the item "Dispatch would rather take a chance with safety than cancel a flight." The international students strongly agreed. This was another worrying trend in flight operations interaction of the university. It could be a result of the operational tempo of contract training, which sometimes requires that international student to fly under some pressure to meet company deadlines.

U.S. students disagreed with the item "Management is more concerned with making money than being safe," while the international students agreed. The international students agreed with the item "Management does not show much concern for safety until there is an accident or incident," while the U.S. students disagreed. The international students agreed that "Management schedules CFIs as much as legally possible with little concern for their sleep schedule or fatigue," while the U.S. students disagreed. The U.S. students disagreed that "Management tries to get around safety requirements whenever they get the chance." The international students agreed with the item. The perceptions of the international students were consistent in their mean responses and reflected their poor outlook of the prevailing safety culture in the flight program. This could also imply a gap in alignment of safety promotion coverage in their contract training. Safety culture assessment is a dynamic process and requires establishing a baseline for comparison. The safety culture will have to be subjected to periodic and continuous assessment to be able to build a confident database for comprehensive analysis. Due to changes in procedures, operations, and even the human components, the safety culture of an organization will always evolve; safety staff and management will 
need to continuously review the effectiveness of the safety management system (International Civil Aviation Organization, 2009).

Finally, as part of the discussion, it should be noted that the results and discussions of the study were limited to the study sample, and care must be taken not to make generalizations for all collegiate aviation programs since safety culture is dynamic and could vary due to different procedures; types of operations; and changes in management, equipment, regulations, environment, and population. However, the methodology and process could be adapted to conduct safety culture assessments in other collegiate aviation programs. The study assumed that all international contract students had a proficient reading and written comprehension level of the English language since the survey was in English.

\section{Recommendations}

Safety assurance is a cyclic process even when the SMS is fully matured, since there will always be the need for periodic review and continuous improvement (Stolzer et al., 2011). Safety culture studies should be continued with other populations in the university's flight program such as ATC, maintenance, and UAS personnel. There should also be an assessment of the perceptions of university aviation management on the safety culture and the results correlated with the perception of students to be able to gauge the vertical extent of SMS saturation.

Another area that requires study is building a good fit model of leading indicators like perception, attitude, and behavior and using it as a predictor of lagging indicators (safety outcome) like incidents, accidents, and violations (IATA, n.d.). It is also recommended that further studies be conducted in other collegiate aviation programs and the results cross validated to build a useable database for predictive safety studies. It is recommended that the FAA, university aviation programs in the US, and industry players provide funds for an intercollegiate safety culture assessment research program to provide a baseline for the implementation and continuous improvement of SMS in universities.

The proposed research on safety culture assessment and SMS will establish the necessary structures before the FAA adopts a final rule on SMS for Part 141 training organizations in the near future. Finally, more studies should also be conducted on the effect of national culture on the perceptions and behavior of foreign students in flight training programs of U.S. universities which are implementing SMS.

\section{Conclusion}

As part of the implementation of a Safety Management System in a four-year Part 141 collegiate aviation program, a safety culture assessment was conducted to determine the perception of flight students and flight instructors on the safety culture in the flight program. A safety culture perception survey of a sample of flight students and instructors was conducted using a modified survey called CAPSCAS.

The study revealed that there were significant variances in the perception of respondents on the safety culture by year groups and the variance could potentially arise due to different flight operational experience levels and years spent in the flight program. There was an observed trend that the more years and time spent in the aviation program, the better the perception of the safety culture. This was reflected in the responses among the year groups. Significantly, the responses between the juniors and freshmen showed that, while the juniors had a very favorable perception of the safety culture, the freshmen had less favorable perception of the safety culture. There should be a proactive review of the safety education program to better suit the characteristics of these aviation student populations as part of the SMS implementation. There should be more attention and emphasis of the safety program for freshmen and new personnel in the flight program.

There were also significant differences in the perceptions of resident U.S. students and international contract students on the program's safety culture. The differences could be a result of prior or dissimilar operational experiences, language, and cultural environment. Generally, the U.S. students had a more favorable perception of the safety culture than the international contract students. The international students had a perception that pilots who called in sick or fatigued were scrutinized by flight management personnel. The international students also perceived that pilots had little or no authority to make decisions that affect flight safety. The international students also had a perception that pilots who are new or less senior were unwilling to speak up regarding flight safety issues.

The international students also had a perception that management did not show much concern for safety until there was an accident or incident and that management tries to get around safety requirements whenever they get the chance. The international students also had a perception that flight management personnel were unavailable when pilots need help. Finally, the international students had a perception that they were gambling with the safety of the aircraft any time they went on a training activity.

The study shows that there is a need to modify and restructure the safety promotion program for international contract students which will take their specific national culture and differences into consideration. Management should ensure that a proactive effort is put in place to bridge the national culture and safety expectations of the international contract students with the university's aviation safety culture so that there will be less safety misalignment. The safety alignment could be achieved through detailed 
and modified safety promotion curricula. Management should ensure a more pronounced presence of safety personnel/staff in contract training during the initial phase of training at the university and periodic recurrent safety promotional activities in order to close such safety gaps.

\section{References}

Australian Transport Safety Bureau. (2004, May). ATSB Aviation Safety Survey: Safety Climate Factors [PDF]. Canberra, Australia: Australian Transport Safety Bureau. Retrieved from https://www.atsb.gov.au/ media/36879/Safety_climate_factors.pdf

Bjerke, E. (2011). Annual safety presentation to UND Safety Council: Student survey results. Grand Forks: University of North Dakota Safety Council.

Block, E. E., Sabin, E. J., \& Patankar, M. S. (2007). The structure of safety climate for accident free flight crews. International Journal of Applied Aviation Studies, 7(1), 46-59. Retrieved from http://www.faa.gov/ about/office_org/headquarters_offices/arc/programs/academy/journal/ pdf/Spring_2007.pdf

Bos, P., \& Lu, C.-t. (2007, August/September). Safety Management Systems: A primer. Airport Magazine, 19(5), 44-48. Retrieved from http://airportmagazine.net/issues/2007-2/

Cooper, M. D. (2000). Towards a model of safety culture. Safety Science, 36(2), 111-136. http://dx.doi.org/10.1016/S0925-7535(00)00035-7

Cortina, J. M. (1993). What is coefficient alpha? An examination of theory and applications. Journal of Applied Psychology, 78(1), 98-104. http:// dx.doi.org/10.1037/0021-9010.78.1.98

Creswell, J. W. (Ed.). (2009). Research design: Qualitative, quantitative, and mixed method approaches (3rd ed.). Thousand Oaks, CA: SAGE Publications, Inc.

Cronbach, L. J. (1951). Coefficeint alpha and the internal structure of tests. Psychometrika, 16(3), 297-334. http://dx.doi.org/10.1007/BF 02310555

Dekker, S. (2007). Just culture: Balancing safety and accountability. Hampshire, England: Ashgate Publishing, Ltd.

Dillman, B., Voges, J., \& Robertson, M. (2011). Safety occurrences: Student perceptions regarding failure to report. Journal of Aviation Management and Education, 1. Retrieved from http://www.aabri.com/ manuscripts/09261.pdf

Evans, B., Glendon, A. I., \& Creed, P. A. (2007). Development and initial validation of an aviation safety climate scale. Journal of Safety Research, 38(6), 675-682. http://dx.doi.org/10.1016/j.jsr.2007.09.005

Fanjoy, R. O., \& Gao, Y. (2011). Learning styles of Chinese aviation students. International Journal of Applied Aviation Studies, 11(1), 5765. Retrieved from http://www.faa.gov/about/office_org/headquarters offices/arc/programs/academy/journal/pdf/Summer_2011.pdf

Federal Aviation Administration. (2007). Air traffic organization Safety Management System: Order JO 1000.37 [PDF]. Washington, D.C.: Federal Aviation Administration. Retrieved from http://www.faa.gov/ documentlibrary/media/order/nd/1000.37.pdf

Federal Aviation Administration. (2008). Safety Management System Guidelines: Order 8000.369 [PDF]. Washington, D.C.: Federal Aviation Administration. Retrieved from http://www.faa.gov/ documentLibrary/media/Order/8000.369.pdf

Federal Aviation Administration. (2010a, February 05). Aviation safety: Safety Management System (SMS). Retrieved from http://www.faa.gov/ about/initiatives/sms/

Federal Aviation Administration. (2010b, August 12). Safety Management Systems for aviation service providers: AC 120-92A [PDF]. Washington D.C.: Federal Aviation Administration. Retrieved from http://www.faa.gov/regulations_policies/advisory_circulars/index.cfm/ go/document.information/documentID/319228
Federal Aviation Administration. (2010c, September 20). Safety Management System: Frequently Asked Questions. Retrieved from http://www.faa.gov/about/initiatives/sms/faq/

Federal Aviation Administration. (2012). Safety Management System (SMS) for Pilot Schools and Training Centers. Washington, D.C.: Air Traffic Organization NextGen \& Operations Planning, Office of Research and Technology Development.

Federal Aviation Administration. (2013, July 30). Safety Management System: SMS Pilot Projects Overview. Retrieved from http://www.faa. gov/about/initiatives/sms/pilot_projects/overview/

Field, A. (2009). Discovering statistics using SPSS (3rd ed.). London, England: SAGE Publications, Ltd.

Gibbons, A. M., von Thaden, T. L., \& Wiegmann, D. A. (2006) Development and initial validation of a survey for assessing safety culture in commercial flight operations. The International Journal of Aviation Psychology, 16(2), 215-238. http://dx.doi.org/10.1207/ s15327108ijap1602_6

Gordon, R., \& Kirwan, B. (2004). Developing a safety culture in a research and development environment: Air traffic management domain. Proceedings from the Europe Chapter of the Human Factors and Ergonomic Society Conference. Brétigny-sur-Orge, France: Eurocontrol Experimental Centre.

Hofstede, G. (1980). Culture's consequences: International differences in work-related values. Newbury Park, CA: SAGE Publications, Inc.

Hofstede, G., \& Hofstede, G. J. (2004). Cultures and organizations: Software of the mind (2nd ed.). New York, NY: McGraw-Hill.

Hunter, D. R. (2006). Risk perception among general aviation pilots. The International Journal of Aviation Psychology, 16(2), 135-144. http:// dx.doi.org/10.1207/s15327108ijap1602_1

International Air Transport Association. (n.d.). IATA operational safety audit (IOSA). Retrieved from http://www.iata.org/whatwedo/safety/ audit/iosa/Pages/index.aspx

International Air Transport Association. (2011). Safety Management Systems: Implementation and controls handbook. Montreal, Canada: IATA Training and Development Institute.

International Civil Aviation Organization. (2002). Line oriented safety audit manual (Doc 9803, AN 761 [1st ed.]). Montréal, Canada: International Civil Aviation Organization.

International Civil Aviation Organization. (2009). Safety Management Manual (SMM) (Doc. 9859 [2nd ed.]) [PDF]. Montréal, Canada: International Civil Aviation Organization. Retrieved from http://www. icao.int/safety/fsix/Library/DOC_9859_FULL_EN.pdf

Joy, S., \& Kolb, D. A. (2009). Are there cultural differences in learning style? International Journal of Intercultural Relations, 33(1), 69-85. http://dx.doi.org/10.1016/j.ijintrel.2008.11.002

Kanki, B., Helmreich, R., \& Anca, J. (Eds.). (2010). Crew resource management (Vol. 2). San Diego, CA: Academic Press.

Lercel, D., Steckel, R., Mondello, S., Carr, E., \& Patankar, M. (2011, February). Aviation Safety Management System return on investment study. St. Louis, MO: Center for Aviation Safety Research, Parks College of Engineering, Aviation, and Technology, St. Louis University. Retrieved from http://parks.slu.edu/myos/my-uploads/ 2013/01/03/aviation-safety-management-systems-roi-study.pdf

Lu, C.-t., Young, J., Schreckengast, S., \& Chen, H. (2011). Safety culture: The perception of Taiwan's aviation leaders. International Journal of Applied Aviation Studies, 11(1), 27-45. Retrieved from http://www.faa. gov/about/office_org/headquarters_offices/arc/programs/academy/ journal/pdf/Summer_2011.pdf

Lu, C.-t., Przetak, R., \& Wetmore, M. (2005). Discovering the non-flight hazards and suggesting a safety training model. International Journal of Applied Aviation Science, 5(1), 135-152. Retrieved from http:// www.faa.gov/about/office_org/headquarters_offices/arc/programs/ academy/journal/pdf/Spring_2005.pdf

Patankar, M. S. (2003). A study of safety culture in an aviation organization. International Journal of Applied Aviation Studies, 3(2), 
243-258. Retrieved from http://www.faa.gov/about/office_org/ headquarters_offices/arc/programs/academy/journal/pdf/Fall_2003.pdf

Perezgonzalez, J. D. (2009). ICAO: Human factors, management and organization. AviationKnowledge. Retrieved from http://aviation knowledge.wikidot.com/aviation3:icao-hf10

Piers, M., Montijn, C., \& Balk, A. (2009). Safety culture framework for the ECAST SMS-WG. European Commercial Aviation Safety Team (ECAST). Retrieved from https://easa.europa.eu/essi/ecast/wpcontent/uploads/2011/08/WP1-ECASTSMSWG-SafetyCultureframe work1.pdf

Reason, J., \& Hobbs, A. (2003). Managing maintenance error: A practical guide. Aldershot, England: Ashgate Publishing, Ltd.

Simon, S. I., \& Cistaro, P. A. (2009, April). Transforming safety culture: Grassroots-led/management-supported change at a major utility. Professional Safety, 28-35.

Stevens, J. P. (2002). Applied multivariate statistics for the social sciences (4th ed.). Mahwah, NJ: Lawrence Erlbaum Associates.

Stolzer, A. J., Haldford, C. D., \& Goglia, J. J. (2011). Implementing Safety Management Systems in aviation. Surrey, England: Ashgate Publishing, Ltd.

Ullrich, G. (2012). Safety Mangement System implementation phases 1 \& 2 report. Grand Forks: University of North Dakota Aviation.

von Thaden, T. (2008). Safety culture in commercial aviation operations: Technical report HFD-08-3/FAA-08-1. Savoy, IL: University of Illinois Human Factors Division.

von Thaden, T. L., \& Gibbons, A. M. (2008, July). The Safety Culture Indicator Scale Measurement System (SCISMS) [PDF]. Washington,
D.C.: Office of Aviation Research and Development. Retrieved from http://www.tc.faa.gov/logistics/grants/pdf/2001/01-G-015.pdf

von Thaden, T. L., Kessel, J., \& Ruengvisesh, D. (2008). Measuring indicators of safety culture in a major European airline flight operations department. Proceedings from Eighth International Symposium of the Australian Aviation Psychology Association. Sydney, Australia: Aviation Psychology Association. Retrieved from http://atcvantage.com/docs/culture_von_Thaden_Safety_Culture_ AAvP_2008.pdf

von Thaden, T. L., Wiegmann, D. A., \& Shappell, S. A. (2006). Organizational factors in commercial aviation accidents. International Journal of Aviation Psychology, 16(3), 239-261. http://dx.doi.org/10. 1207/s15327108ijap1603_1

Wensveen, J. G. (2010, February 23). The airline industry: Trends, challenges, strategies [PDF]. Retrieved from http://webauthtest.econ. usyd.edu.au/_data/assets/pdf_file/0010/67789/johnw-presentation.pdf

Wiegmann, D. A., Zhang, H., von Thaden, T. L., Sharma, G., \& Gibbons, A. M. (2004). Safety culture: An integrative review. International Journal of Aviation Psychology, 14(2), 117-134. http://dx.doi.org/10. 1207/s15327108ijap1402_1

Wood, R. H. (2003). Aviation safety program: A management handbook (3rd ed.). Englewood, CO: Jeppesen Sanderson, Inc.

Yule, S. (2003). Senior management influence on safety performance in the UK and US energy sectors (Doctoral dissertation). Retrieved from http://homepages.abdn.ac.uk/s.j.yule/pages/dept/Yule_safety\%20climate\% 20and\%20culture\%20review.htm 